\title{
The Role of Modelling and Simulation in the Preparations for Flight Trials Aboard the Queen Elizabeth Class Aircraft Carriers
}

\author{
Dr. M F Kelly, Wh.Sch., AMIMechE ${ }^{a}$, N A Watson, MEng ${ }^{a}$, Dr. S J Hodge, MIET, MRAeS, MAHS ${ }^{b}$, Dr. M \\ D White ${ }^{a}$, Prof. I Owen, FIMechE ${ }^{a *}$
}

${ }^{a}$ The University of Liverpool, Liverpool, UK; ${ }^{b}$ BAE Systems, Warton, UK

*Corresponding author. Email:i.owen@liv.ac.uk

\begin{abstract}
Synopsis
This paper provides a brief overview of how modelling and simulation has been used to inform preparations for First of Class Flight Trials (FOCFT) aboard HMS Queen Elizabeth, the first of the United Kingdom's two new Queen Elizabeth Class aircraft carriers, from the perspective of a collaborative research programme undertaken by industry and academia to develop high-fidelity simulations of the carrier's 'airwake'. Computer modelling of the unsteady air flow over the carrier, and of the aircraft flight dynamics, have been integrated into high-fidelity flight simulators at BAE Systems Warton, and at the University of Liverpool. The Queen Elizabeth Class (QEC) carriers have primarily been designed to operate the Short Take-Off and Vertical Landing (STOVL) variant of the Lockheed Martin F-35 Lightning II multirole fighter aircraft and will also operate a range of rotary-wing assets. Computational Fluid Dynamics (CFD) has been used to compute the time-varying air flow over and around the $280 \mathrm{~m}$ long ship, along the F-35B landing approach path and up to $400 \mathrm{~m}$ astern of the ship. The paper shows a selection of results from the full-scale CFD analysis, and the results from a small-scale experiment that was conducted to provide confidence in the validity of the computed airwakes. The QEC airwakes have been employed by BAE Systems in its fixed-wing flight simulator at Warton, where test pilots have conducted simulated deck landings for a variety of wind over deck conditions, so providing experience for F-35B test pilots and the ship's Flying Control (FLYCO) crew ahead of FOCFT, which will be conducted later this year. Airwakes have also been implemented in the HELIFLIGHT-R flight simulator at the University of Liverpool, where helicopter landings to the QEC have been simulated using a generic medium-weight maritime-helicopter model. A selection of results from the helicopter flight simulator trials is presented in terms of the workload ratings reported by test pilots, and these are related to the characteristics of the computed airwake at the landing spots tested. The paper demonstrates how modelling and simulation can be used to reduce both the risk and cost of flight trials, by informing the FOCFT planning process, and by highlighting, in advance of the trials, which wind speed and azimuth combinations may require more focus.
\end{abstract}

Keywords: HMS Queen Elizabeth; Flight Simulation; Ship aerodynamics; Computational Fluid Dynamics; Ship Helicopter Operating Limits

\section{Introduction}

Engineering Modelling and Simulation $(M \& S)$ is the solution of practical engineering analysis and design problems using physics-based computational models. Once these simulations have been created, and validated to demonstrate how well they represent the real system, they can be used to safely explore the performance of the system for a large variety of conditions. This paper will illustrate how M\&S has been used to simulate deck landings to the UK's new Queen Elizabeth Class (QEC) aircraft carriers in advance of real at-sea flight testing.

HMS Queen Elizabeth (Figure 1), the first of the United Kingdom's two new aircraft carriers, was commissioned in December 2017 and has already successfully conducted sea-trials and rotary-wing flight testing; the second carrier in the class, the HMS Prince of Wales, is currently at an advanced stage of construction. At 65,000 tonnes each, with a length of $280 \mathrm{~m}$ and a beam of $73 \mathrm{~m}$, they are the largest and most capable warships ever to be built for the Royal Navy.

The QEC carriers have been primarily designed to operate the Lockheed Martin F-35B Lightning II (Figure 2) which is the world's first supersonic stealth Short Take-Off and Vertical Landing (STOVL) fighter jet (Bevilaqua, 2009). Characteristic features of the QEC, as can be seen in Figure 1, include the twin island superstructure, and the ramp, or "ski-jump", located at the bow to facilitate short take-off (Fry et al., 2009). The concurrent development of the QEC and F-35 programmes has presented a unique opportunity to deploy M\&S to optimise the aircraft-ship interface and maximise the combined capabilities of these two assets (Lison, 2009). As well as the fixed-wing F-35B, it is expected that the QEC carriers will also operate a range of rotary-wing assets including Merlin, Wildcat, Chinook and Apache helicopters. 


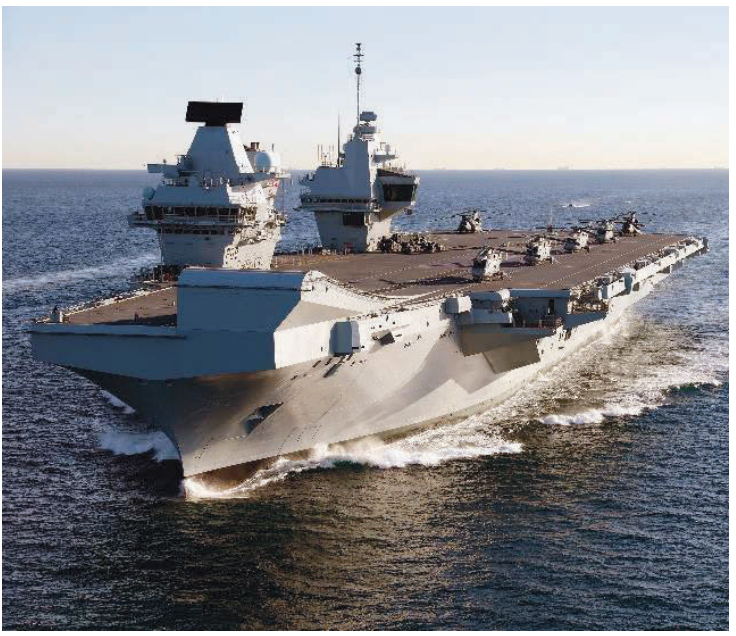

Figure 1: HMS Queen Elizabeth during sea trials

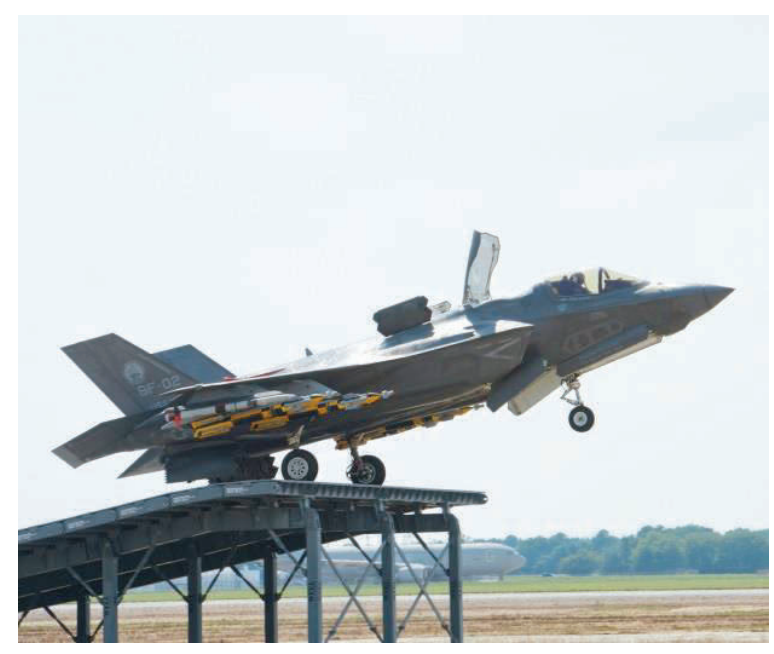

Figure 2: Lockheed Martin F-35B during land-based ski-jump testing at NAS Patuxent River

Although the flight deck of the QEC covers an area of approximately four acres, the space available for an aircraft to manoeuvre will be constrained by other aircraft, personnel and equipment on deck. In rough seas the pilot will have to land on a pitching, rolling and heaving deck, and may have to contend with the presence of highly dynamic air flow over the flight deck. This phenomenon, known as the ship's 'airwake', is caused by the air flowing over and around the flight-deck edges and superstructure as a result of the combined effect of the prevailing wind and the forward motion of the ship. The combination of unsteady ship motion and airwake is collectively referred to as the 'dynamic interface' (Hodge et al., 2012).

The environment in which maritime aircraft operate can, therefore, be challenging, and operational limits do exist, which must be adhered to. Typically, these limits are expressed in terms of wind over deck magnitude and direction, and ship motion, and will define the operational envelope for each aircraft type operating from the ship. These envelopes are traditionally determined through a process known as First of Class Flight Trials (FOCFT), in which numerous deck landings are carried out in a variety of wind, ship motion and visual conditions. Recently, simulation technology, including motion platforms, visual projection systems and high-performance computing, has advanced to the stage where it is now feasible to use high-fidelity simulation to augment at-sea testing. This paper presents an overview of a flight simulation facility that has been developed at BAE Systems, Warton, specifically to support the F-35B/QEC clearance and qualification process. The paper will also describe the generic research flight simulator at the University of Liverpool (UoL), HELIFLIGHT-R (White et al., 2012), and will present a selection of results from helicopter flight trials conducted in that facility.

\section{Modelling and simulation of the aircraft-ship dynamic interface}

The main components required to construct a high-fidelity simulation of the aircraft-ship dynamic interface are shown in Figure 3. These components are specifically related to the flight simulator at BAE Systems, Warton, for an F-35B operating to and from the QEC. Components similar to those shown in Figure 3 have also been integrated into the UoL research simulator. The following sections give a brief description of each of the simulation components; note that certain restricted features were not implemented in the UoL simulator.

\subsection{The air vehicle model}

The air vehicle model used in the BAE Systems simulator is a comprehensive non-linear simulation of the F-35 aircraft, developed by Lockheed Martin Aeronautics and its partners. The model is constructed from a set of federated sub-system components, each being designed, built, validated and maintained by the appropriate domain experts. These subsystem models cover the entire range of aircraft systems, including but not limited to: aerodynamics, flight controls, air-data systems and sensors, propulsion systems, actuators, landing gear, electrical power, navigation and vehicle management systems. 


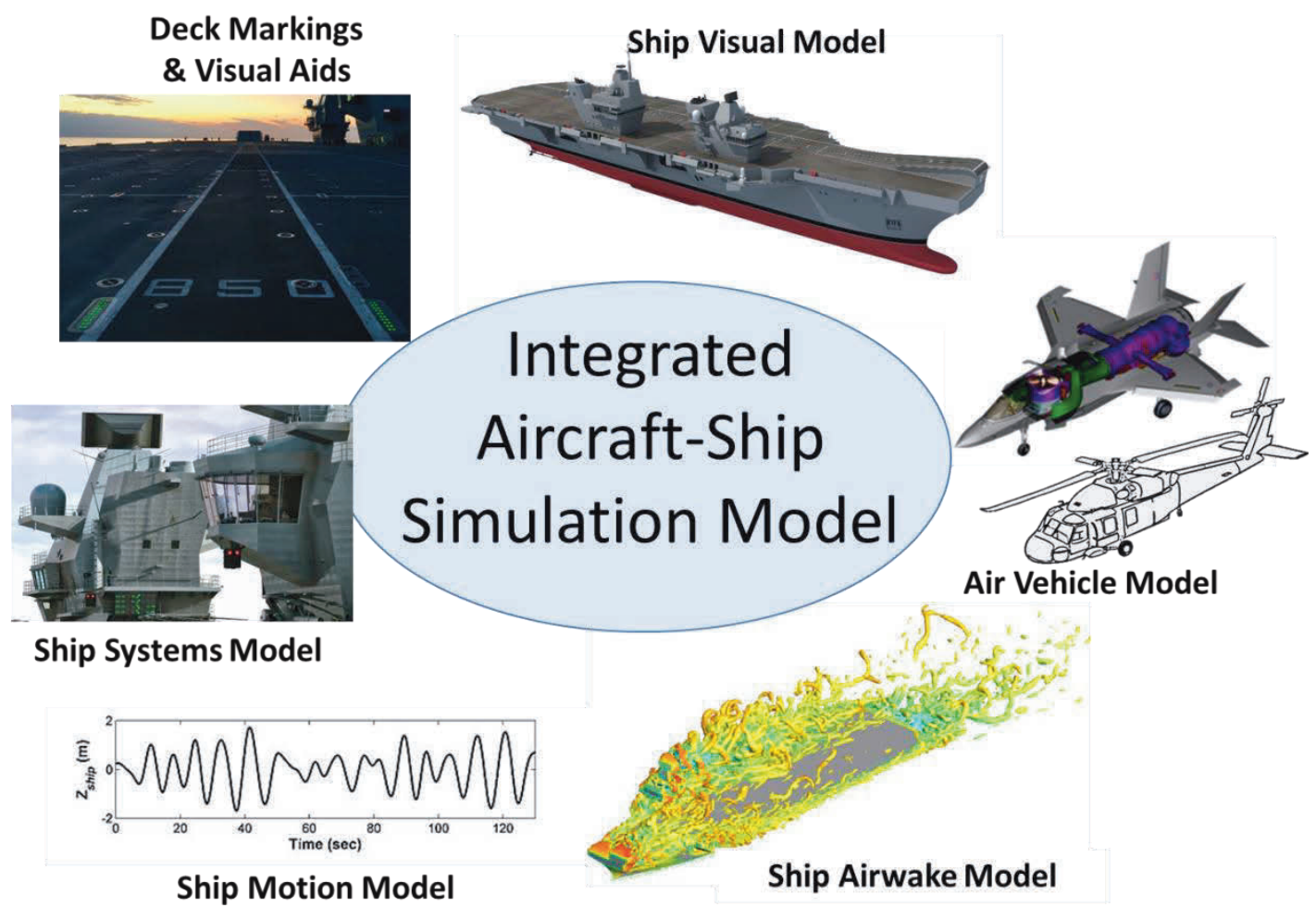

Figure 3: Principal components of an integrated aircraft-ship simulation

The air vehicle model used in the UoL HELIFLIGHT-R simulator is a generic medium-weight maritimehelicopter, configured to represent a Sikorsky SH-60B Seahawk. This aircraft was selected because of the availability of engineering data in the open literature for that type of helicopter (Beck and Funk, 1994), and because it has been widely used by UoL in its research into maritime helicopter operations to frigates and destroyers (Hodge et al., 2012). The model was developed in FLIGHTLAB and comprises the following major subsystem components: (1) individual blade-element main-rotor model including look-up tables of non-linear lift, drag and pitching moment coefficients stored as functions of incidence and Mach number; (2) a Bailey disk tailrotor model, (3) finite-state Peters-He dynamic inflow model; (4) separate aerodynamic look-up tables for the fuselage, vertical tail and the port and starboard stabilator forces and moments stored as nonlinear functions of incidence and sideslip; (5) turbo-shaft engine model with a rotor-speed governor; (6) primary mechanical flight control system and Stability Augmentation System (SAS) models including sensor and actuator dynamics; and (7) a landing gear model to provide deck reaction cues on touchdown.

\subsection{The ship visual model}

A three-dimensional model of the QEC was developed from general arrangement CAD data supplied by the Aircraft Carrier Alliance (ACA). Pilots often use relatively small features on the island superstructures as position and height reference cues while hovering alongside and over the deck, so the level of detail incorporated into the ship visual model is an important factor in creating a realistic and immersive cueing environment.

\subsection{The deck markings and visual landing aids}

The actual deck markings and Visual Landing Aids (VLA) were designed by the ACA and their VLA suppliers. Models of the VLA and deck markings were incorporated into the visual model of the ship (Hodge, 2004). These models define the size, shape, colour and position of each VLA or deck marking and, for VLAs, the brightness, viewable angle/range and signal format (e.g. colours, flash rate, duty cycle etc.). 


\subsection{The ship systems model}

This models the ship's sensors and systems, specifically those relating to the launch and recovery of fixedand rotary-wing aircraft (e.g. Inertial Measurement Units (IMUs), anemometers and meteorological systems, approach radar, and VLA control algorithms etc.). These systems are primarily used to derive data for the displays and controls within the FLYCO simulation environment (see Section 4,1) (e.g. air traffic radar displays and meteorological information displays).

\subsection{The ship motion model}

This model represents the sea-keeping characteristics of the vessel. Realistic ship motion data have been derived from a series of tank test experiments conducted by the ACA and integrated into the BAE Systems simulation. The ship motion model employed in the HELIFLIGHT-R simulator incorporates a generic set of ship motion data used at UoL which can be scaled to represent a range of different sized ships.

\subsection{The ship airwake model}

These have been created at UoL using Computational Fluid Dynamics (CFD) techniques. For high-fidelity flight simulation it is essential that the airwake is computed using time-accurate CFD, i.e. the three components of velocity in the airwake are computed at different time intervals (every 0.01 seconds in this case) so that unsteady velocities can be imposed on the air vehicle model as it is 'flown' through the airwake. The generation of the CFD airwakes, their implementation into a real-time flight simulator and their experimental validation, is a major part of the M\&S process for the dynamic interface and will be discussed in greater detail below.

\section{QEC airwake modelling}

As noted above, for $M \& S$ to be exploited successfully the individual models and the overall simulation must be validated with real-world data to give confidence that the simulation results can be trusted. Creating unsteady CFD airwakes over a ship the size of the QEC, and for a significant distance downstream of the ship, where the disturbed air can still affect the aircraft, is a significant challenge. While UoL has a wealth of experience in creating CFD airwakes for smaller ships, such as Type 23/45 frigates and destroyers, and Wave Class tankers (Owen et al., 2017; Forrest and Owen, 2010), the significantly larger QEC presents a new challenge and so smallscale experiments have been conducted to compare measured data with the CFD-generated airwakes. The approach taken has been to conduct the experiments at a 1:200 scale and to apply the CFD technique at this scale to replicate the experiment. The experiment was carried out by immersing a $1.4 \mathrm{~m}$ long model of the QEC in a water tunnel at the UoL and using a three-dimensional velocity probe to measure the three components of unsteady velocity at numerous positions around the ship. The same CFD technique was applied to the full-scale ship and, in this case, an Atmospheric Boundary Layer (ABL) profile, typical of those measured over the open ocean (Garratt, 1992), was applied to the freestream air flow at the inlet ahead of the ship. A detailed description of the CFD analysis is beyond the scope of the current paper but, overall, the agreement between the small-scale CFD and the experiment is excellent, as will be demonstrated below, and the comparison between the full-scale and small-scale CFD is also very good, differing only in areas where differences were expected (e.g. due to the very different Reynolds numbers of the flow at the two scales, and the inclusion of the ABL in the full-scale computations). A more complete description of the experiment and the CFD is given by Kelly (2018).

Research at UoL into ship airwakes and their integration with piloted flight simulation over the past decade or more has shown that it is essential to create airwakes using time-accurate CFD techniques, so that irregular timevarying velocity components are applied to the aircraft flight dynamics model providing a realistic experience for the pilot, in terms of handling qualities and workload (Owen et al., 2017). Delayed Detached-Eddy Simulation (DDES) lends itself well to the application of modelling the unsteady flow around bluff bodies such as ships, since DDES combines a Reynolds Averaged Navier-Stokes (RANS) approach to modelling turbulence in the near-wall boundary-layer, whilst resolving turbulent features in separated flow regions using Large-Eddy Simulation (LES) (Spalart et al., 2006); this leads to relatively modest computational requirements compared with pure LES due to relaxation of the near-wall mesh requirements.

One concern with the application of CFD to ship airwake modelling is the potential for artificial dissipation of turbulent energy, especially in the region downstream of the ship; this may be attributed in part to the overly dissipative sub-grid scale model applied when the turbulent length-scale is less than the grid spacing in LES mode. 
To adequately capture turbulent eddies passing over the ship using a DDES solver, it was therefore necessary to refine the mesh size to carefully control the grid density within the CFD region of interest, or 'focus region'. In the current application of aircraft launch and recovery operations from the QEC, the focus region is the area through which aircraft will pass on approach to the ship during the Vertical Landing (VL), which is the primary means of recovery, the Shipborne Rolling Vertical Landing (SRVL) and the ski-jump take-off. The SRVL is a new recovery method unique to the UK F-35B/QEC and involves the aircraft recovering along a $7^{\circ}$ glideslope over the stern of the ship, at a low forward speed, and stopping on deck using the wheel-brakes (Atkinson et al., 2013; Cook et al., 2010). The advantage of the SRVL over the traditional 'hover-translate-land' technique is an additional capacity to recover to the ship at higher gross weights (e.g. with more fuel and/or stores), by using wing-lift to augment the lift available from the propulsion system. Figure 4 shows the CFD focus region which extends approximately 1.5 ship lengths aft of the ship.

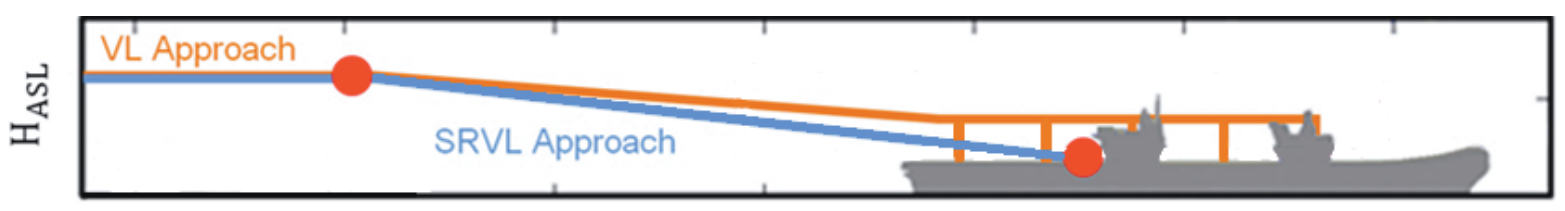

$x$ distance from ship CG

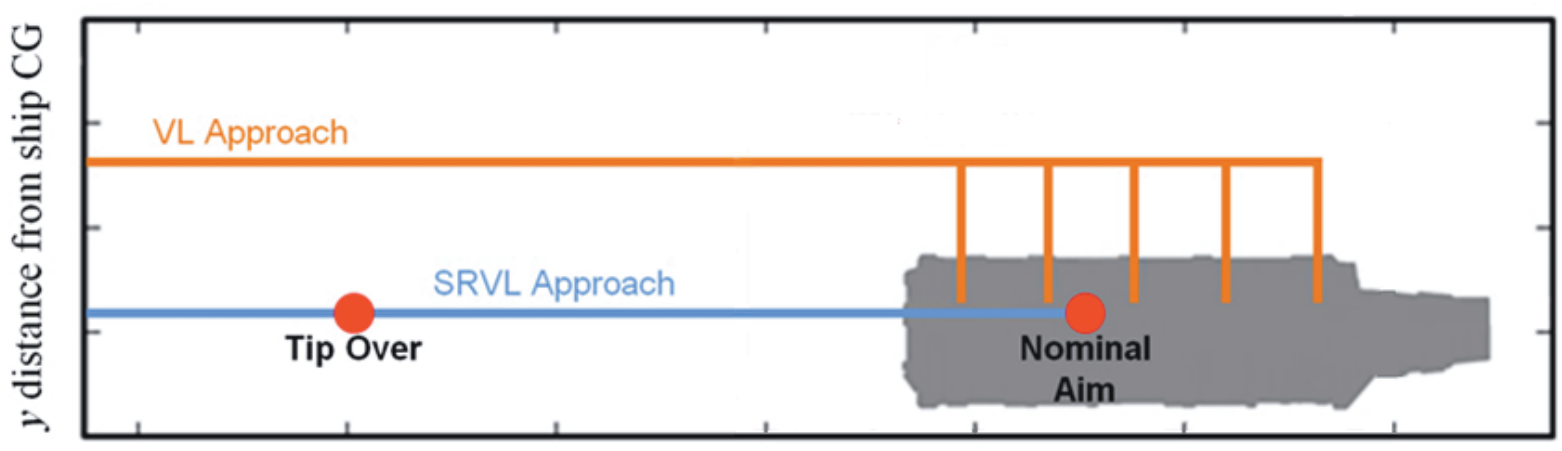

Figure 4: CFD focus region and nominal aircraft recovery profiles

\subsection{Small-scale CFD study}

The CFD technique was first applied to the small-scale ship model immersed in the water channel. Experiments were carried out with the ship aligned with the flow to represent a headwind, and with it rotated so that the flow approached from $10^{\circ}$ off the starboard side. The flow approaching the ship had a uniform vertical velocity profile, and the Reynolds number based on the length of the 1:200 scale model was about $1.4 \times 10^{6}$ (compared with about $2 \times 10^{8}$ for the full-scale ship in a 20 knot headwind). Figure 5 shows the instantaneous flow over the ship where the turbulent vortical structures are presented as Q-criterion isosurfaces, coloured by instantaneous streamwise velocity (normalised by freestream velocity). Q-Criterion is a widely used parameter in CFD studies to identify and visualise vortices (Haller, 2005). The results presented in Figure 5 were also used to inform the experiments. From an operational perspective the areas of interest are the landing spots, which are along the flight deck where, in a headwind, there is little disturbance to the flow; the exception to this is Spot 6, which is a helicopter landing spot, located on the starboard side directly behind the aft island and is, therefore, within the turbulent wake from the islands (the six vertical landing spots are indicated as black dots on Figure 5). In contrast, from the perspective of comparing experimental data with CFD solutions, the areas around the bow of the ship, the islands and astern of the ship are of greater interest; experimental velocity measurements were, therefore, concentrated in these areas. Also shown in Figure 5 are the $x, y, z$ axes relative to the ship. The $x$ axis is parallel to the ship centreline, positive towards the stern; $y$ is athwartships, positive to starboard; and $z$ is in the vertical direction, positive upwards. The corresponding velocities in these axes are $u, v$ and $w$, respectively. 


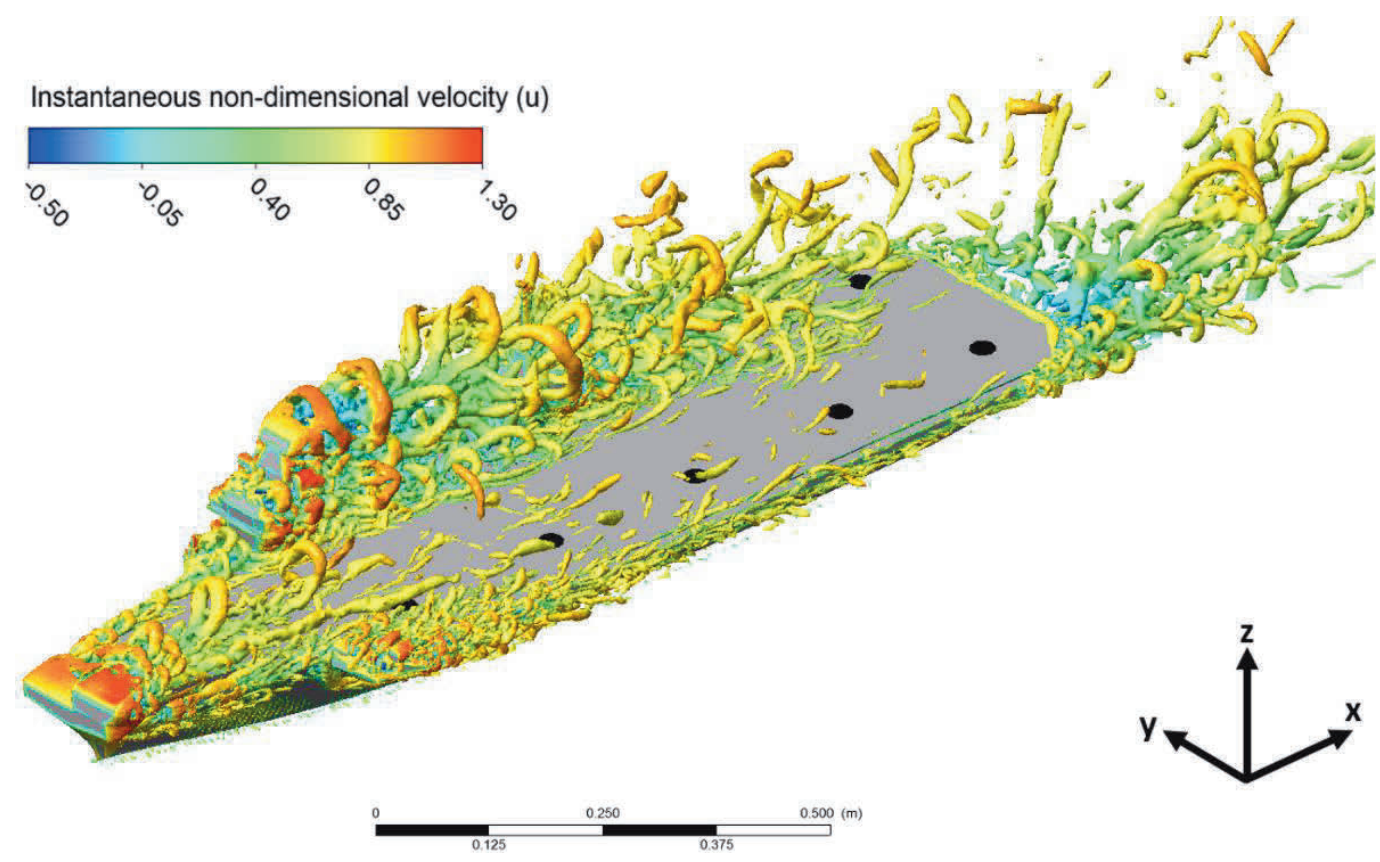

Figure 5: Headwind flow as instantaneous isosurfaces of Q-criterion coloured by $u$-velocity

Velocity measurements were therefore taken at various locations around the ship, to enable comparison with the CFD results. Of particularly interest were the measurements taken on a plane through the centreline of the islands where the air flow is most disturbed, and also around the bow and stern of the ship, over the flight deck, and along the SRVL glideslope astern of the ship. Figure 6 shows a comparison of the mean streamwise velocities along vertical lines at various positions over and astern of the ship, in a vertical plane passing through the centre of the islands. The airwake is illustrated by contours of turbulence intensity, which is defined as the root mean square of the velocity component divided by the freestream flow velocity (i.e. not the local velocity).

It can be seen from Figure 6 that ahead of the forward island the $u$-velocity profile above the deck is largely undisturbed, whereas in the lee of each of the islands and at the stern of the ship there is a significant velocity deficit compared with the freestream. Also, referring to the contours of turbulence intensity, the turbulence between the islands is of the order of 20\%. As can be seen from Figure 6, the agreement between the CFD (red lines) and the measured data (black lines) is encouraging. Similar agreement was seen in other areas of the flow, and in the $v$ and $w$ velocity components, as well as in the turbulence intensities. A CFD comparison with measured data has also been made for the freestream flow coming from $10^{\circ}$ off the starboard bow; however, these data, which also show good agreement, are omitted here for the sake of brevity.

Of particular importance for approaching aircraft is the flow astern of the ship. Figure 7 shows the vertical $w$-velocity component plotted along the SRVL approach path for the headwind condition; in this instance the vertical plane corresponds with the centreline of the ski-jump ramp, since that is the pilot's line-up reference cue. Again, the agreement between the CFD and experiment can be seen to be very good. As can be seen in Figure 7, there is a distinctive downward velocity component located at the stern of the ship; a feature known colloquially as the 'burble' (Polsky, 2005). In a headwind the blunt-stern of the ship essentially presents a backward-facing step where air flow will separate from the deck to form a three-dimensional recirculation zone immediately aft of the ship, the flow passing over the stern will therefore be deflected downwards towards the surface of the sea. This downwash will tend to disturb the aircraft from its ideal flightpath causing it to sink, unless compensated for by corrective action from the pilot or automatic guidance system (Denham, 2016; Hess, 2018). The burble is a well-documented phenomena experienced by conventional fixed-wing carrier pilots, who will generally be approaching a carrier at a much shallower angle (nominally $3^{\circ}$ ) and will, therefore, pass much closer to the stern compared to the F-35B/QEC's SRVL manoeuvre (nominally $7^{\circ}$ ), thus experiencing a stronger downwash. 


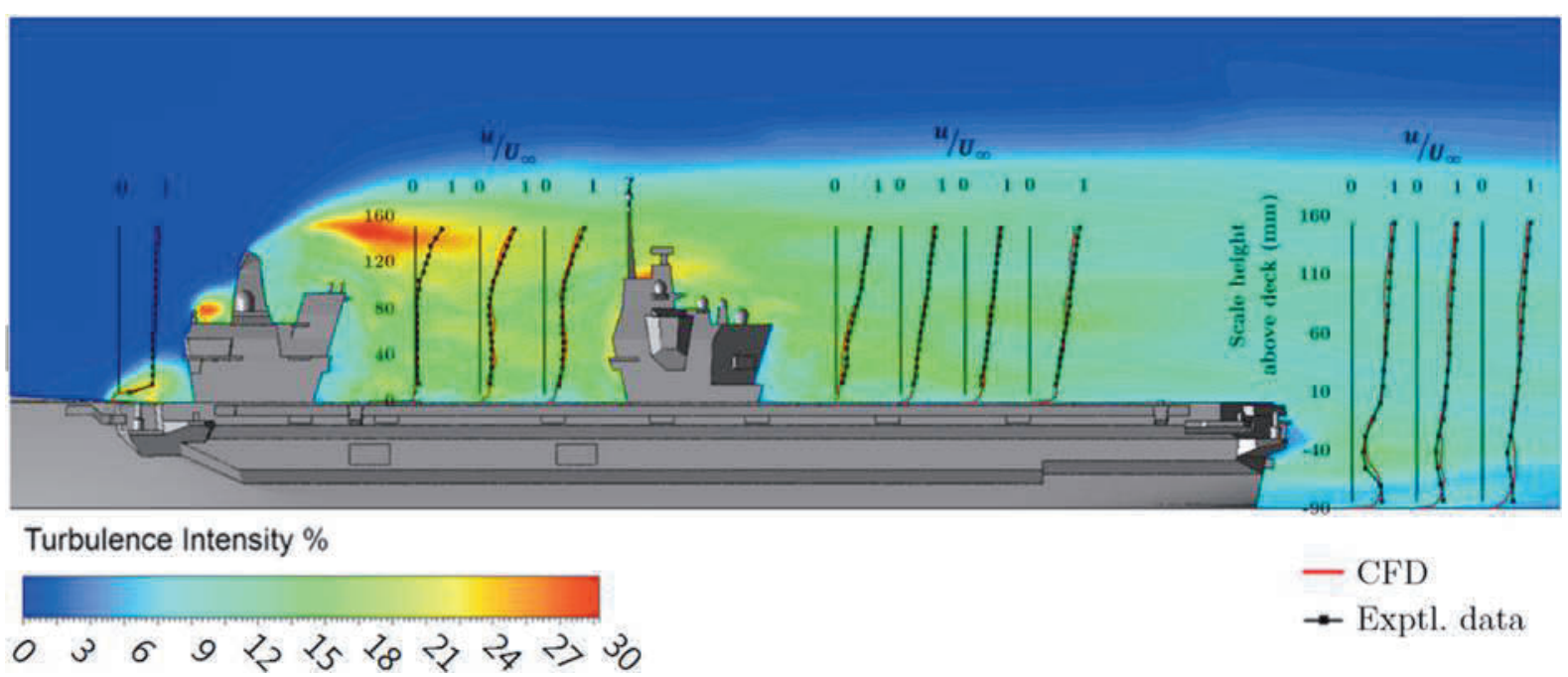

Figure 6: Comparison of experiment and CFD mean $u$-velocity in plane through centre of islands

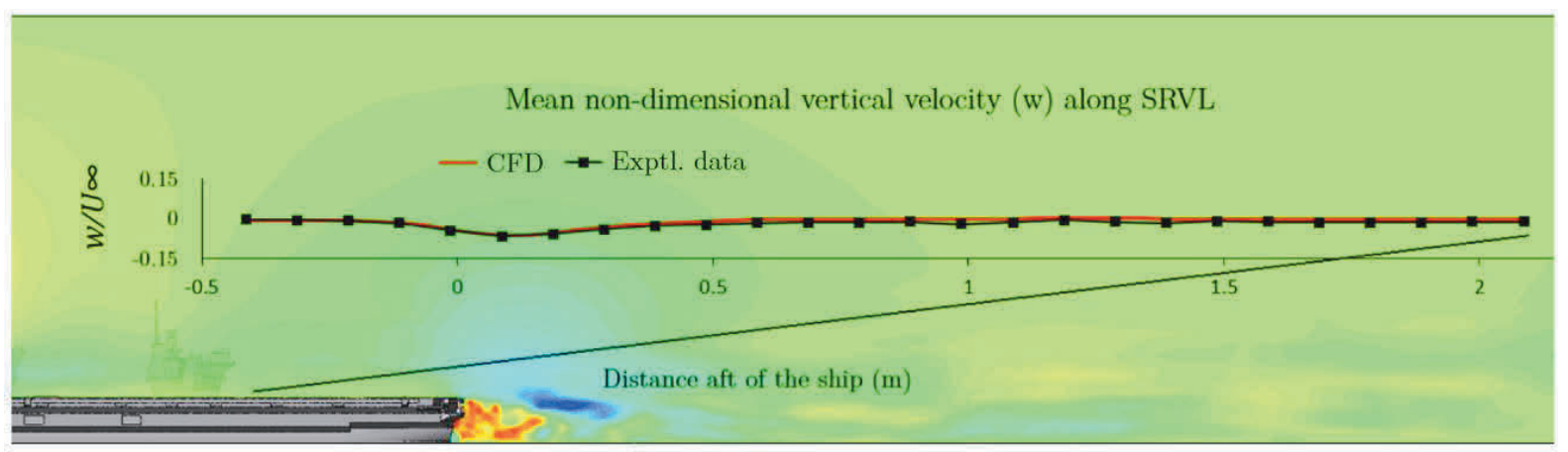

Mean non-dimensional vertical velocity (w)

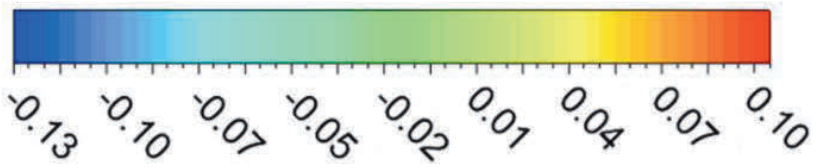

Figure 7: Comparison of experiment and CFD mean $w$-velocity along $7^{\circ}$ SRVL glideslope

\subsection{Full-scale CFD study}

While the small-scale CFD study reported in the previous section modelled the flow in the confined working section of the water channel, the full-scale CFD is on a much larger scale; not just because of the size of the ship, but also the necessary size of the computational domain in which it is placed. Details of the process are described by Kelly (2018), who also discusses how the oceanic ABL was applied to the model. Figure 8 illustrates the airwake over the full-scale ship in a headwind, as contours of mean $u$-velocity in a plane through the centre of the islands. The ABL profile, defined as a power law, is shown ahead of the ship (black line).

The CFD-generated air flow over the full- and small-scale ships were found to be very similar in all areas, with the exception being at the bow of the ship, where the combined effects of the flow Reynolds number, and the application of an ABL at full-scale, were expected to affect the local flow-field somewhat. The difference over the ski-jump is shown in Figure 9, where the small-scale flow (red line) separates from the surface as it passes over the rounded leading edge of the ski-jump ramp, but the full-scale flow (black dashed line) shows no such tendency to separate. Ahead of the ship it can be seen that the oncoming velocity profile is uniform for the smallscale CFD, reflecting the conditions in the water channel, while at full-scale the profile is that of the applied ABL. It is noticeable that by the end of the ramp the two flows are practically identical. 


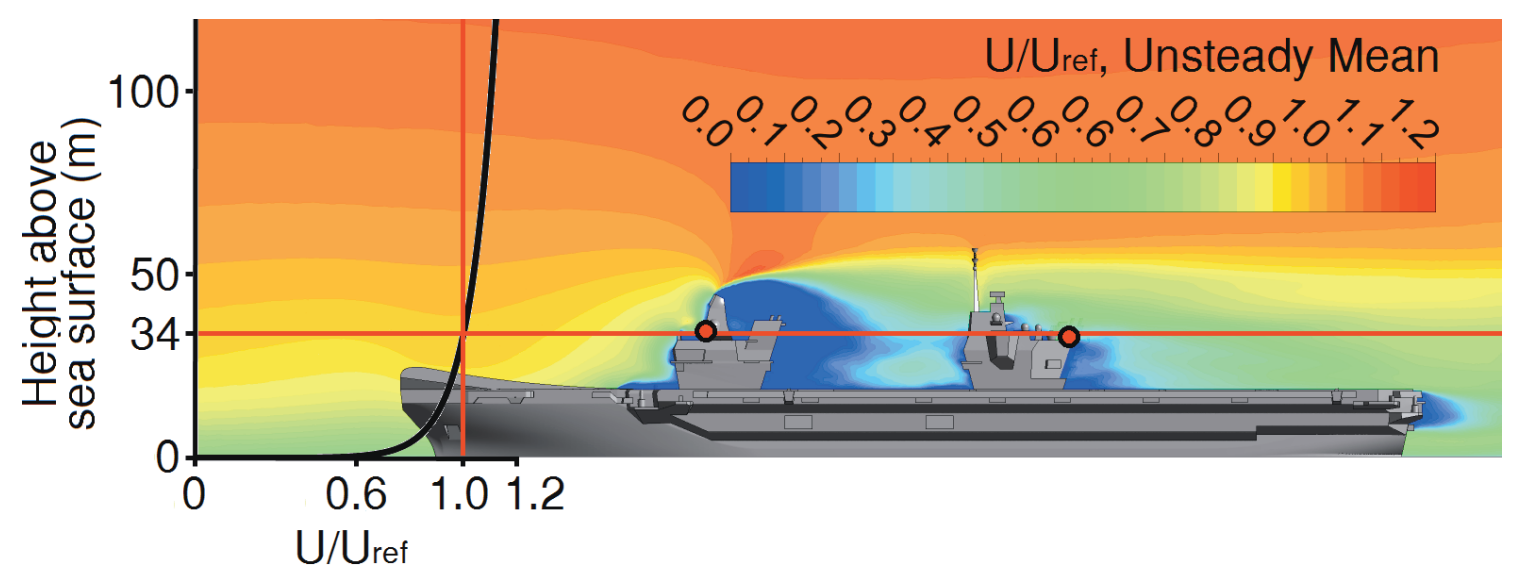

Figure 8: Contours of mean normalised $u$-velocity components in plane through centre of islands and ABL

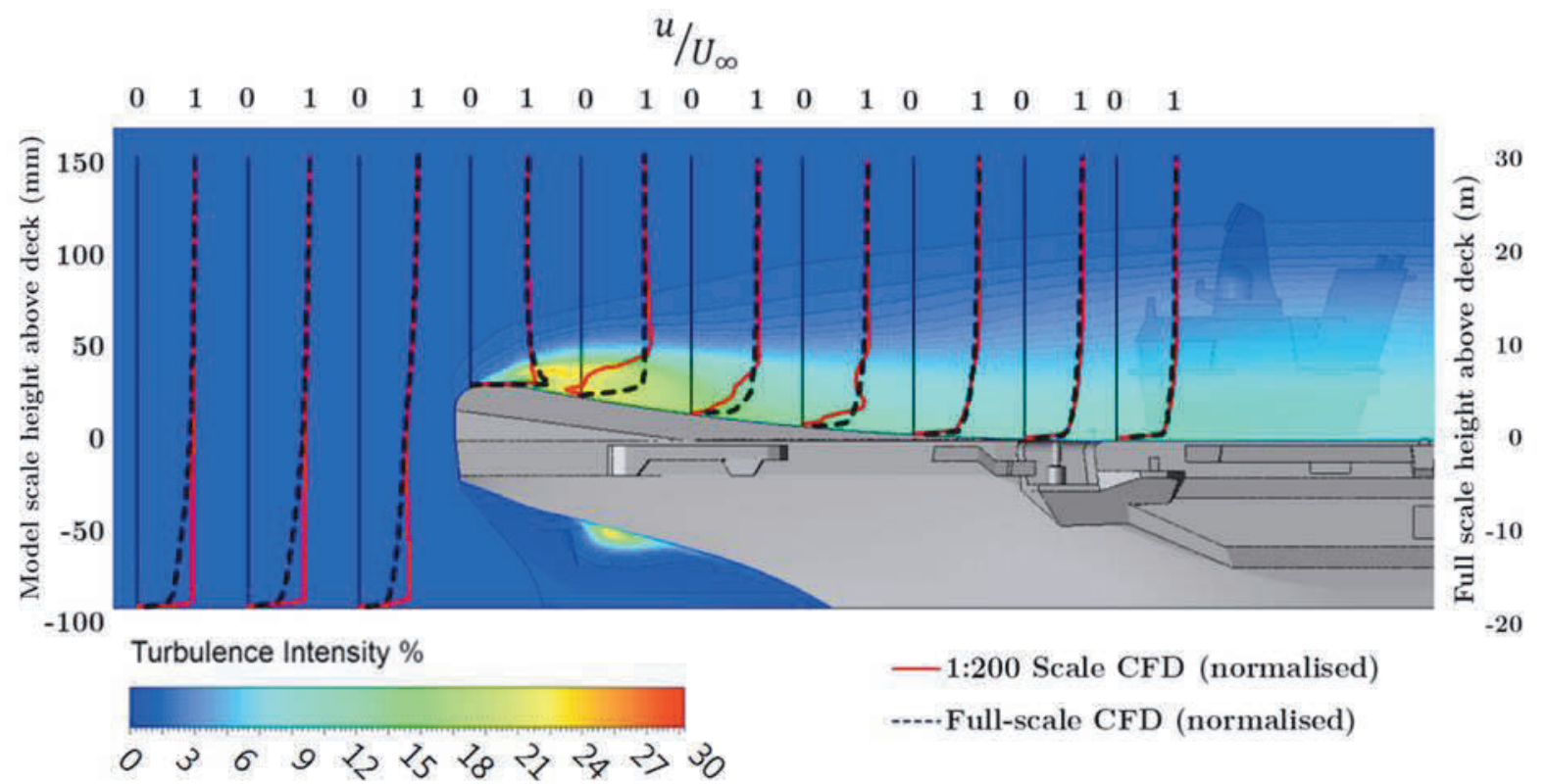

Figure 9: Comparison of small-scale and full-scale CFD $u$-velocity component over the ski-jump

\section{Flight simulation}

As described earlier, flight simulation has been conducted in both the F-35B/QEC integration simulator at BAE Systems, and the HELIFLIGHT-R research simulator at the UoL. These two facilities will be described in the following sections, including some results from helicopter landings in the UoL simulator.

\subsection{Fixed-wing simulation}

The bespoke F-35/QEC integration simulator at BAE Systems, Warton, has played, and continues to play, a vital role in the development and qualification of the F-35/QEC aircraft-ship interface (Hodge and Wilson, 2008; Hodge et al., 2013). The simulator includes a fully representative F-35 cockpit, mounted on a six-axis electric motion system, housed inside a fixed $3.65 \mathrm{~m}$ radius dome (Figure 10). The cockpit is an accurate replica of the F35B cockpit (Figure 11), including active sidestick and throttle units, a large-area touchscreen display and ejection seat model. A flight standard Helmet-Mounted Display System (HMDS) has also been integrated to provide pilots with flight guidance and navigation symbology. The motion system uses the state-of-the-art electric-motion technology, although the actuator stroke length $(640 \mathrm{~mm})$ is considerably shorter than most civil airline training simulators; the fact that the visual system is mounted off-board (i.e. not mounted on-top of the moving platform) 
reduces platform payload resulting in a highly agile motion system with a relatively small footprint. The visual system uses 16 WQXGA projectors, the images from each being seamlessly blended to provide the pilot with a continuous field-of-view of $360^{\circ}$ in azimuth by $100^{\circ}$ in elevation. The projected scene includes a high-fidelity model of the QEC carrier together with a realistic and dynamic sea surface.

The piloted simulator is networked with a second, adjacent simulator facility which provides a replica of the QEC Flying Control or FLYCO environment (Figure 12), which on the QEC carriers is located in the aft island. The outside world scene in this simulator presents the view from FLYCO including pre-recorded F-35B and rotorcraft take-off and recovery manoeuvres, as well as live flights being conducted by the pilot in the flight simulator. This allows the ship's FLYCO team, including the Landing Signal Officer (LSO), who together with the pilot is responsible for the safe launch and recovery of fixed-wing aircraft to the ship, to work together to refine the Concept of Operations (CONOPS) dictating how fixed-wing aircraft will operate from the carrier. Over the past two years test pilots and LSOs from the UK Royal Navy and Royal Air Force, and the F-35 Integrated Test Force (ITF) have used these facilities to 'fly' thousands of simulated deck landings and ski-jump launches to gather the necessary data to ensure that the real-life flight trials, to be conducted later this year, are as safe, efficient and effective as possible.

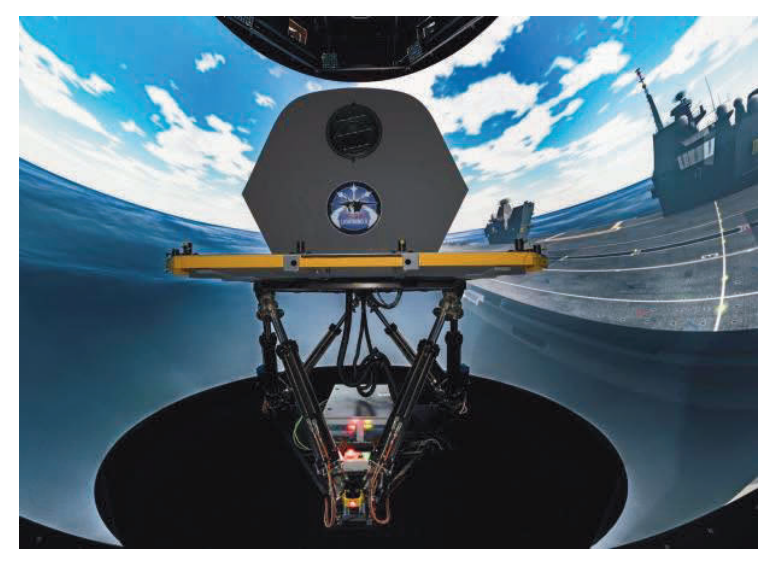

Figure 10: F-35/QEC simulation facility at BAE Systems Warton, showing motion system and dome

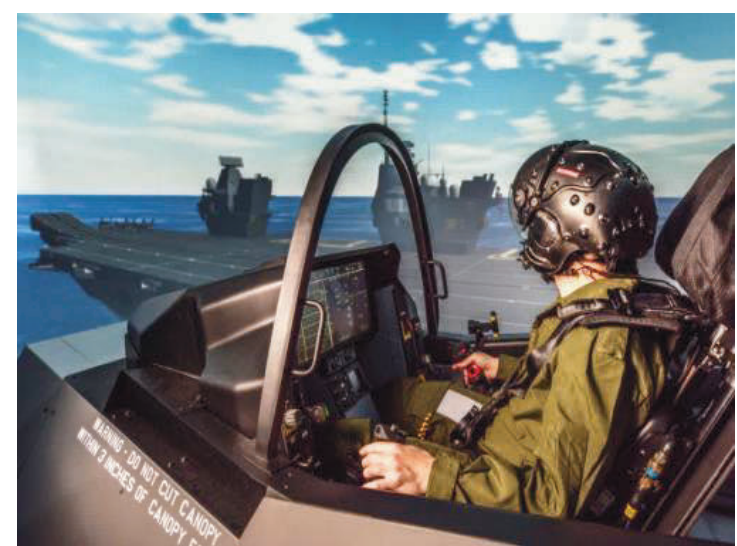

Figure 11: F-35/QEC simulation facility at BAE Systems Warton, showing inside of cockpit

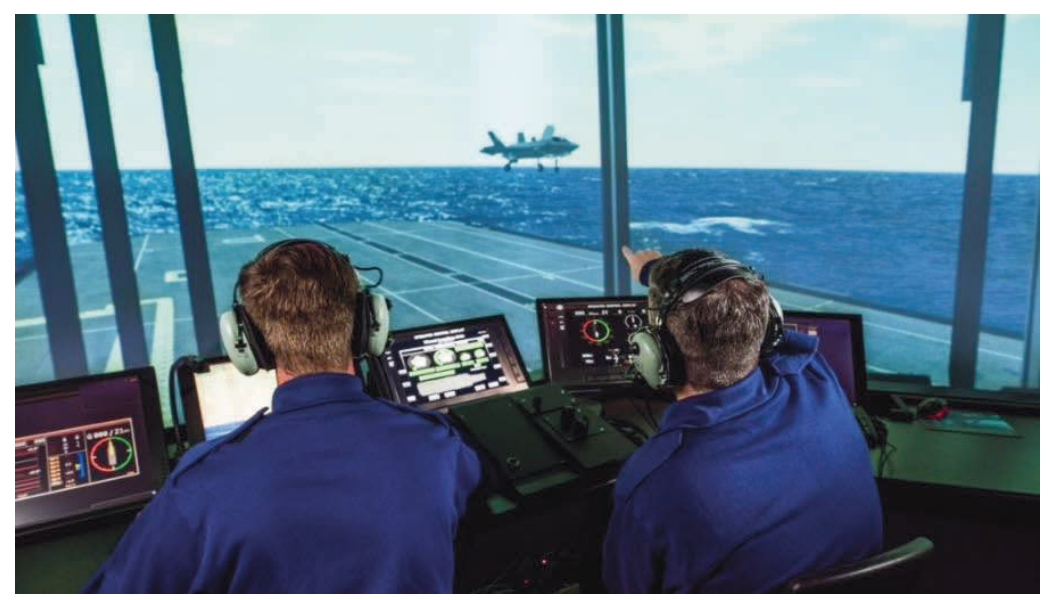

Figure 12: F-35/QEC simulation facility at BAE Systems Warton, showing inside of networked FLYCO simulator

\subsection{Rotary-wing simulation}

The University of Liverpool's HELIFLIGHT-R facility, Figure 13, is a fully reconfigurable research simulator, consisting of a generic rotorcraft cockpit housed inside a $12 \mathrm{ft}$ diameter visual display dome, mounted on a motion platform. The motion platform is of the standard hexapod configuration, comprising six electricactuators each with a 24 inch stroke. The simulator cabin houses a twin-seat cockpit, with a third seat at the rear 
for an instructor or simulator operator. The primary cockpit instruments are presented on two wide-screen flatpanel displays. A four-axis electronic control loading system provides the capability to configure the force-feel characteristics of both the pilot and co-pilot's cyclic, collective and pedal controls to represent a wide range of aircraft types. Three Liquid Crystal on Silicon $(\mathrm{LCoS})$ projectors, with a resolution of 1,400 by 1,050 pixels, are used to project an outside-world image onto the inside surface of the dome. The three images are geometrycorrected and edge-blended, before being projected, so as to present a single continuous image to the pilot in the cockpit (Figure 14). The projectors are equipped with wide-angle lenses and provide a horizontal field-of-view of $200^{\circ}\left( \pm 100^{\circ}\right)$ and a vertical field-of-view of $60^{\circ}\left( \pm 30^{\circ}\right)$. Audio cues are presented to the pilot using a system of loudspeakers distributed throughout the interior of the cockpit. This facility has been used to conduct the helicopter landings to the QEC described in this paper, as a testbed for pioneering a route to 'end-to-end' integration of the QEC airwake models, and has also been used to research the fidelity requirements for simulator motion cueing in the highly dynamic aircraft-ship interface environment (Hodge et al., 2015).

Integration of the aircraft flight dynamics model with the HELIFLIGHT-R simulator is achieved using Advanced Rotorcraft Technology's (ART) FLIGHTLAB software (DuVal and He, 2018), which provides a library of aircraft models, including a generic rotorcraft flight dynamics model that has been configured to be representative of the Sikorsky SH-60B Seahawk. Although it is recognised that the Seahawk is not in use with the UK Royal Navy, it was nevertheless decided that this aircraft model should be used for these 'proof-ofconcept' simulation trials due to its strong validation and extensive use during previous research at Liverpool. CFD airwakes can be integrated with FLIGHTLAB, enabling unsteady airwake velocities to be imposed upon the aircraft flight dynamics model at various locations on the rotor blades and airframe. During testing, the FLIGHTLAB software allows real-time data monitoring and recording which, together with in-cockpit video and audio recordings, are used for post-trial analysis.

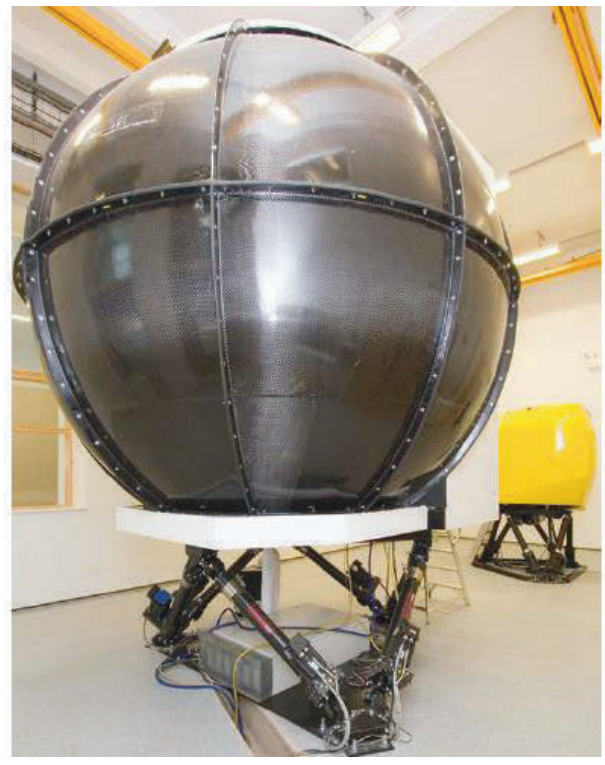

Figure 13: HELIFLIGHT-R research simulator facility at UoL (foreground), external view

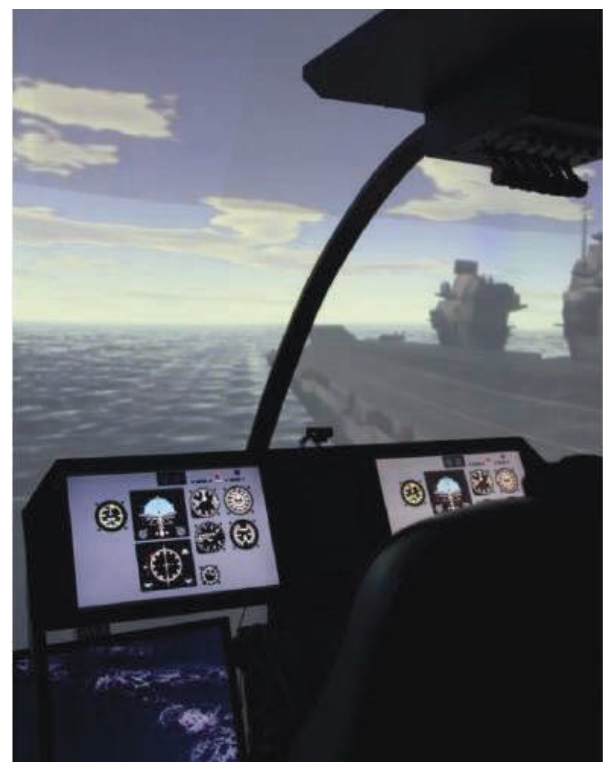

Figure 14: HELIFLIGHT-R research simulator facility at UoL, internal view with QEC visuals

\subsection{Description of Piloted Simulation Experiments}

Once the QEC visual scene, time-varying airwake, and SH-60B Seahawk flight dynamics model had been successfully integrated and tested in the HELIFLIGHT-R flight simulator, a series of piloted experiments were conducted. Thus far trials in the UoL simulator have only been conducted in winds from ahead and from $25^{\circ}$ off the starboard bow to all landing spots, whereas many more wind directions have been investigated in the BAE Systems simulator. In this paper only the results for headwind landings to spots 5 and 6 are presented. The locations of these spots can be seen in Figure 15. In the headwind condition, a helicopter landing to Spot 5 can be expected to be in relatively clean air, while it will be in disturbed air in the lee of the islands when landing to Spot 6. The landings were performed at three wind-speeds: $25 \mathrm{kts}, 35 \mathrm{kts}$ and $45 \mathrm{kts}$. 


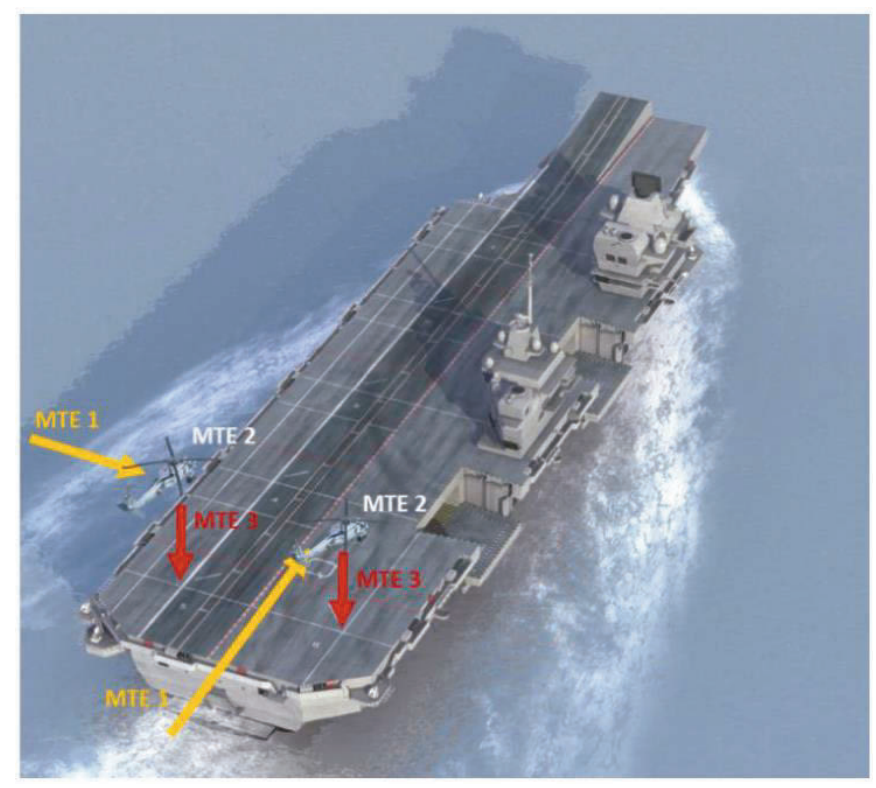

Figure 15: Port-side forward facing approach to Spot 5 and stern approach to Spot 6

For Spot 5, landings were performed by following the standard Royal Navy port-side forward-facing recovery technique (Finlay, 2001), which is typically employed when landing on single-spot frigates and destroyers and is illustrated on the left-hand side of Figure 15. For Spot 6 however, a port-side approach was not deemed appropriate, since the aircraft would have to traverse across almost the entire width of the deck. While an approach from the starboard side was considered feasible, landings to Spot 6 during this experiment were performed using an approach from the stern. The stern approach is shown on the right-hand side of Figure 15.

The landing procedure was split into three contiguous Mission Task Elements (MTEs), with each MTE shown in Figure 15. Starting from a position one rotor diameter off the deck edge, MTE 1 consists of a translation across the flight-deck stabilising at a position above the landing spot, at a hover height of 30ft, in preparation to land. MTE 2 consists of a 30 second period of hover station-keeping prior to the landing. Finally, MTE 3 is the descent from the hover position to touchdown on the flight deck. Note that the requirement to hover for a full 30 seconds during MTE 2 is, in many ways, rather artificial, but it was convenient in an experimental context for ensuring that the pilots experienced the entire airwake time history whilst attempting to maintain station over the deck. A spatial tolerance of $\pm 3.5 \mathrm{~m}$ in all three axes was selected as the desired performance criteria during the hover station-keeping task. The test subjects were two highly experienced former Royal Navy test pilots and the testing was carried out over a period of four days.

The pilots were asked to quantify the workload involved in each deck landing using the 5-point Deck Interface Pilot Effort Scale (DIPES). The DIPES ratings scale is widely used amongst NATO member countries in the determination of operational envelopes for ship-helicopter operations and requires test pilots to rate each landing based on workload (or pilot compensation), performance, accuracy and consistency (Carico et al., 2003). On the DIPES, a numerical rating of 3 or less indicates that deck landings can be repeatedly achieved with precision and safety under the conditions being tested. A rating of 4 or 5 indicates the contrary and would, under normal circumstances, place those conditions outside of the operational envelope. In addition to detailed comments given by the pilot, a number of letter suffixes can also be assigned to each rating, to describe the cause of increased workload (e.g. ' $T$ ' for turbulence or ' $D$ ' for deck motion).

Although the DIPES scale has clearly been optimised for the purpose for which it was intended (i.e. qualification and clearance of ship-helicopter operating envelopes), it is too coarse a scale for assessing what can often be fairly subtle changes in pilot workload throughout a complete landing evolution, due to localised aerodynamic interactions. Therefore, in the simulator, pilot workload for each individual MTE was also gathered using the 10-point Bedford workload ratings scale. Roscoe and Ellis (1990) found that pilots naturally think in terms of spare capacity when considering workload. In the Bedford scale spare capacity is defined as the pilot's ability to carry out secondary tasks, such as maintaining mission awareness, monitoring aircraft systems or listening to radio communications, the primary task being to fly the aircraft through the particular mission or manoeuvre. The higher the workload generated by the primary task, the less spare capacity the pilot will have to 
attend to these secondary tasks. Bedford ratings of 1-3 are awarded where the workload is considered to be satisfactory and does not compromise the pilot's ability to perform secondary tasks, ratings of 4-6 are awarded where the workload is deemed tolerable but attention to secondary tasks is seriously diminished, while ratings of 7-9 indicate that the workload does not allow sufficient attention to secondary tasks but where the pilot can still accomplish the primary task satisfactorily. Finally, a rating of 10 is reserved for situations where workload is so high that the pilot must abandon even the primary task.

\subsection{Experiment Results}

Bedford workload ratings for each MTE and DIPES ratings for each landing evolution are given in Table 1 ; the aerodynamic causes of these ratings will be discussed next, together with an assessment of pilot control activity and aircraft response due to these airwake disturbances. It is noticeable that the two pilots have awarded different ratings on the 10-point Bedford scale; this represents their subjective experience of the test points flown and is typical of piloted simulation experiments, where some degree of 'inter-pilot' variability is to be expected.

As anticipated for a headwind the landing spot inducing the greatest pilot workload was found to be Spot 6 , because of the highly turbulent flow shedding from the ship's islands. Landings at Spot 5 were found to be more benign with lower levels of variation in the instantaneous velocity magnitude and direction found over landing spot. The difference in air flow turbulence intensity over the two spots is clearly shown in the CFD flow visualisation presented in Figure 16.

Table 1: Bedford and DIPES ratings for landings to Spots 5 and 6

\begin{tabular}{|c|c|c|c|c|c|c|}
\hline & & & MTE 1 & MTE 2 & MTE 3 & DIPES \\
\hline \multirow{6}{*}{ PILOT 1} & \multirow{3}{*}{ Spot 5} & $25 \mathrm{kts}$ & 3 & 3 & 3 & 1 \\
\hline & & $35 \mathrm{kts}$ & 3 & 3 & 4 & 1 \\
\hline & & $45 \mathrm{kts}$ & 4 & 4 & 4 & 1 \\
\hline & \multirow{3}{*}{ Spot 6} & $25 \mathrm{kts}$ & 3 & 4 & 4 & 1 \\
\hline & & $35 \mathrm{kts}$ & 4 & 5 & 5 & 1 \\
\hline & & $45 \mathrm{kts}$ & 5 & 7 & 6 & 2 \\
\hline \multirow{6}{*}{ PILOT 2} & \multirow{3}{*}{ Spot 5} & $25 \mathrm{kts}$ & 2 & 2 & 2 & 1 \\
\hline & & $35 \mathrm{kts}$ & 2 & 2 & 2 & 1 \\
\hline & & $45 \mathrm{kts}$ & 2 & 2 & 3 & 1 \\
\hline & \multirow{3}{*}{ Spot 6} & $25 \mathrm{kts}$ & 3 & 3 & 3 & 1 \\
\hline & & $35 \mathrm{kts}$ & 3 & 3 & 3 & 1 \\
\hline & & $45 \mathrm{kts}$ & 3 & 5 & 6 & 3 \\
\hline
\end{tabular}

As can be seen from Table 1, higher wind speed does not necessarily equate to increased pilot workload. For example, while it can be seen that workload will tend to increase with wind speed over Spot 6, where disturbed air flow is encountered, ratings for Spot 5 show a lower correlation between wind speed and pilot workload. This is because pilots performing landings to Spot 5 will experience largely undisturbed air flow, since the only ship geometry ahead of the aircraft is the ski-jump positioned $200 \mathrm{~m}$ away at the bow, and thus pilots will not necessarily award higher workload ratings as the airspeed increases. Landings to Spot 5 were rated as having a consistently lower workload than Spot 6 at all wind speeds by both test pilots. In Figure 17, which shows the helicopter trajectories during the deck landings, the orange boxes represent the limits of desired performance at the height of the aircraft centre of gravity for a $30 \mathrm{ft}$ hover over the deck. As can be seen, both pilots maintained the aircraft position well inside the performance limits of $\pm 3.5 \mathrm{~m}$ assigned to the hover and station-keeping task, particularly at Spot 5 . 


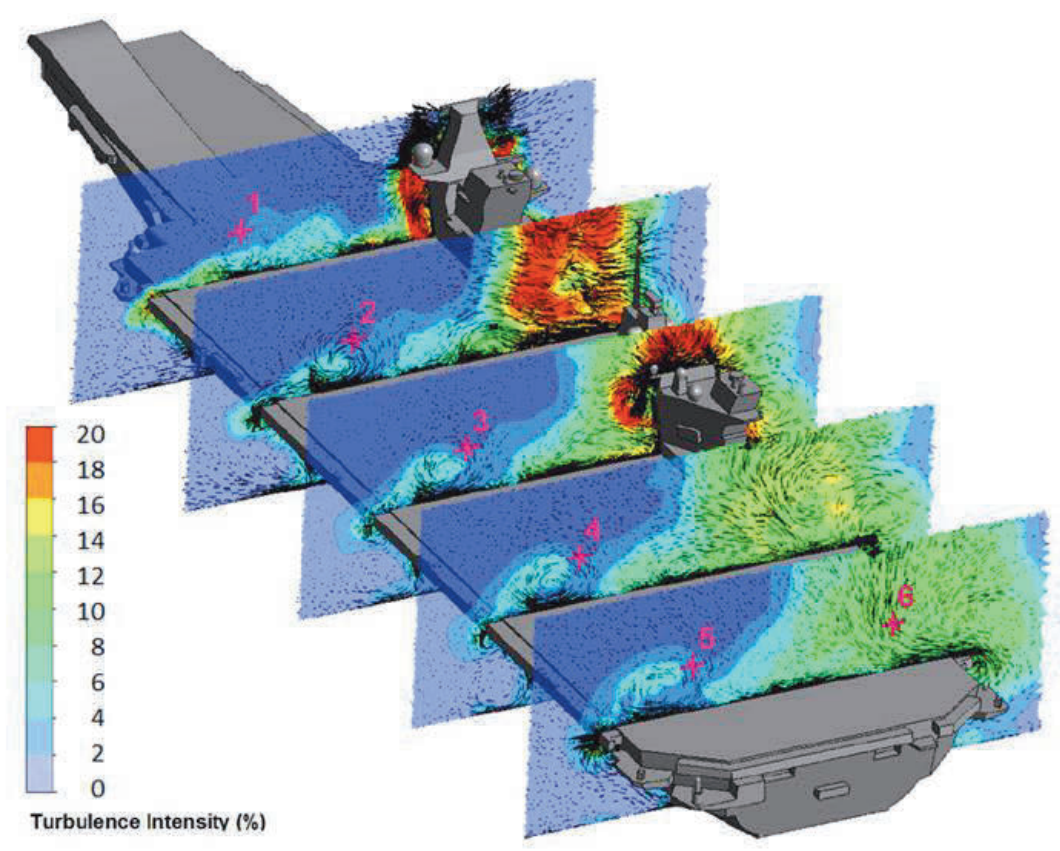

Figure 16: Mean velocity vectors plotted tangentially to contours of mean turbulence intensity

In addition to the increased workload ratings reported by both pilots during landings to Spot 6 , pilot control activity could also be seen to increase when compared with Spot 5, reflecting an increase in the number and amplitude of the corrective inputs required to compensate for the increased disturbances experienced by the aircraft. Throughout landings to Spot 6 it was reported that "aircraft disturbances [were felt] in all axes", however, pilots felt that the dominant axis, in which the highest workload was experienced, was the pitch axis. Analysis of pilot control activity supports this observation, and is shown in Figure 18, where the pilot's lateral and longitudinal cyclic (stick) inputs are plotted for each wind condition for landings to Spot 5 (blue, left) and Spot 6 (red, right). It is clear from Figure 18 that the cyclic control activity required, to maintain an accurate hover position during the station-keeping and landing MTEs, is greater for Spot 6 when compared to Spot 5; as would be anticipated when flying in a more turbulent region of the ship's airwake. Control margin was also eroded at Spot 6 due to the amplitude of the required control inputs and it can be seen that the pilot came within $28 \%$ of the maximum lateral control limit in the $45 \mathrm{kts}$ condition, and within $30 \%$ of the lateral control limit at $35 \mathrm{kts}$ during landings to Spot 6.

\section{Concluding Comments}

This paper has presented a brief overview of one area in which state-of-the-art modelling and simulation research is being applied to shipboard aircraft operations. The paper has described how engineers at BAE Systems are using M\&S to help prepare for and inform the forthcoming fixed-wing First of Class Flight Trials to the QEC aircraft carrier, HMS Queen Elizabeth; results from an exploratory study by the University of Liverpool into rotary-wing operations have also been presented. The paper has focussed on the development, integration and testing of a time-varying model of the ship's airwake using CFD, since this is an essential element of any integrated aircraft-ship simulation. The challenges associated with applying CFD modelling techniques to an aircraft carrier sized vessel at full-scale, both in terms of the necessary computing resources and the special demands, on grid density and domain size, made by fixed-wing approach profiles have also been discussed.

Validation of the resulting airwake model is clearly critical, in order that it may be used, with confidence, as part of the M\&S process being applied to the integration of the F-35 and QEC carriers. Hence, a small-scale experimental study has been conducted, in a recirculating water channel, together with a computational study at the same scale. Comparisons made between the experimental measurements and the small-scale CFD results, and the small-scale and full-scale CFD have demonstrated good agreement, giving confidence in the airwake modelling process. 

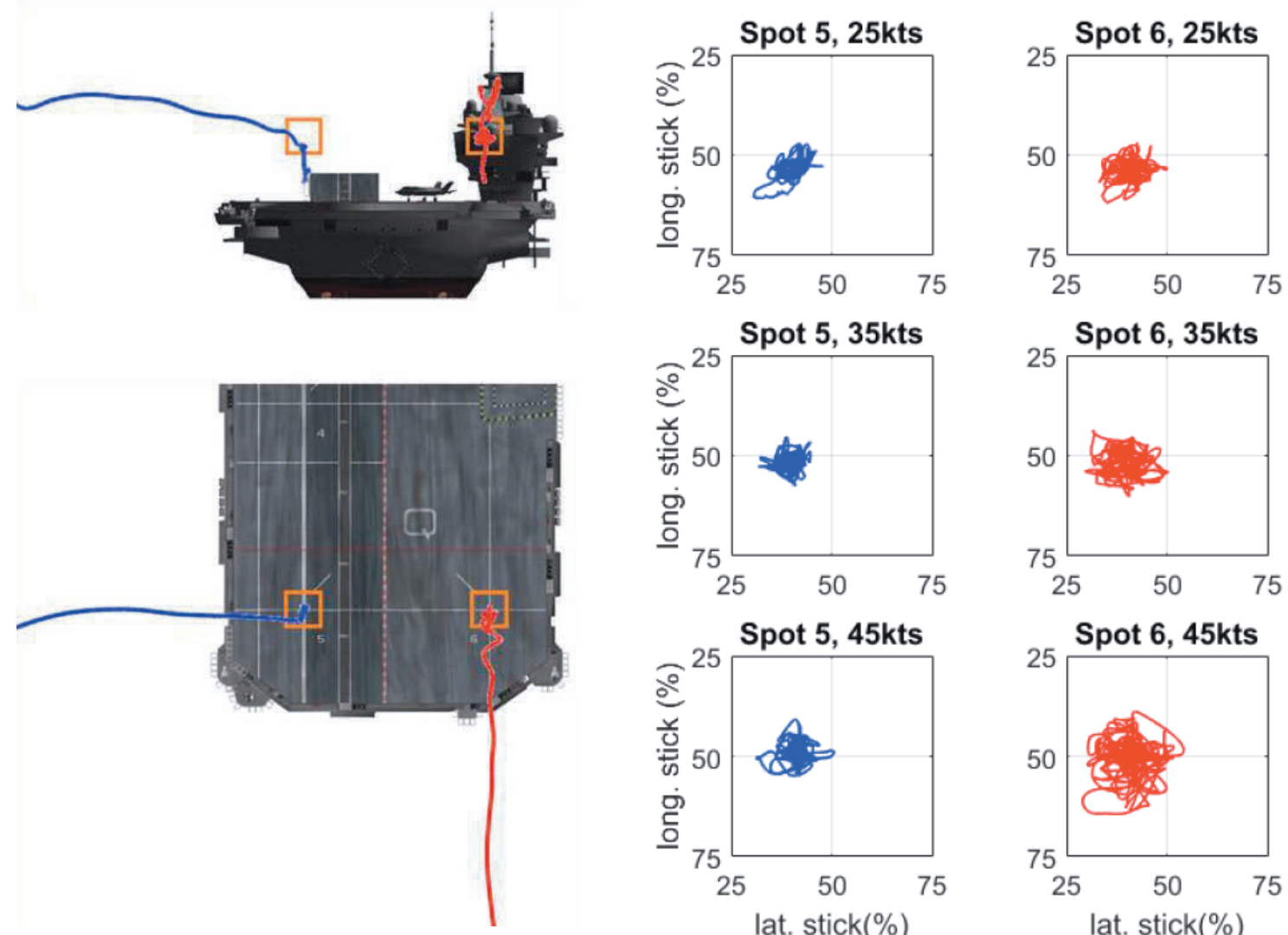

Figure 17: Trace of helicopter center-of-gravity during landings to Spot 5 and Spot 6 with 45kts wind
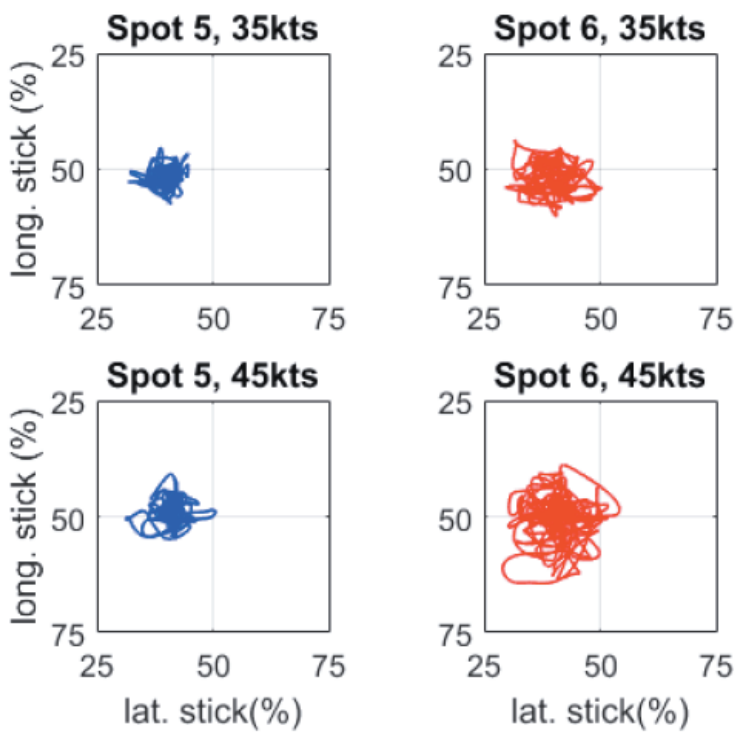

Figure 18: Cyclic control inputs for MTE 2 and 3 for landings to Spot 5 and Spot 6

Consequently, the airwake model has been integrated into two flight simulators, a bespoke F-35B/QEC engineering flight simulator at BAE Systems, Warton, and a generic research simulator at the UoL. Results have been presented from the UoL simulator for an experiment designed to test the 'end-to-end' integration of the airwake with a flight dynamics simulation of a helicopter. Trials with two experienced test pilots have demonstrated the increased difficulty involved in landing in the disturbed air flow, in the lee of the island superstructure, compared with landings performed in a less turbulent region of the ship's flight deck for a headwind. This result was not entirely unexpected, based on practical reasoning and on the results of the computational and experimental studies, and lends further credibility to both the airwake model and the methods used to integrate it into the flight simulator.

Engineers and test pilots have used the simulator at BAE Systems, Warton, employing the same airwake model, to 'fly' thousands of 'virtual' deck landings and ski-jump launches from the deck of HMS Queen Elizabeth in a variety of wind conditions; with the aim of gathering the data to ensure that real-life flight trials will be as safe, efficient and effective as possible. There is clearly no question of these virtual engineering methods being able to supplant at-sea testing at present, nevertheless, intelligent application of M\&S, backed-up by appropriate validation evidence, has been a powerful tool for informing the flight trials planning process. In the future, improvements in computing power and simulation technology are likely to lead to further breakthroughs in the application of $M \& S$ to the challenging aircraft-ship dynamic interface environment, but these improvements must always be underpinned by the type of fundamental research that has been described in this paper. 


\section{Acknowledgements}

This work was jointly funded by an EPSRC CASE Award and BAE Systems. The ongoing support of ANSYS Inc. is acknowledged. Michael Kelly would also like to acknowledge the Joseph Whitworth Trust and Whitworth Society for their continued support during his postgraduate studies.

\section{References}

Atkinson, D., Brown, R., Potts, R., Bennett, D., 2013. Integration of the F-35 Joint Strike Fighter with the UK Queen Elizabeth Class Aircraft Carrier. In: Proceedings of the International Powered Lift Conference, Los Angeles, California.

Beck, C. P., Funk, J. D., 1994. Development and Validation of a Seahawk Blade Element Helicopter Model in Support of Rotorcraft Shipboard Operations. In: Proceedings of the RAeS Rotorcraft Group Conference on 'Rotorcraft Simulation', London, UK.

Bevilaqua, P.M., 2009. Inventing the F-35 Joint Strike Fighter. In: Proceedings of the 47th AIAA Aerospace Sciences Meeting, Orlando, Florida.

Carico, G. D., Fang, R., Finch, R. S., Geyer, W. P., Krijns, H. W., Long, K., 2003. Helicopter/Ship Qualification Testing. In: RTO Technical Report RTO-AG-300-V22.

Chanson, H., Trevethan, M., Koch, C., 2007. Discussion of 'Turbulence Measurements with Acoustic Doppler Velocimeters' by Carlos M. García, Mariano I. Cantero, Yarko Niño, and Marcelo H. García. In: Journal of Hydraulic Engineering, Vol. 133(11), pp 1283-1286.

Cook, R., Atkinson, D., Milla, R., Revill, N., Wilson, P., 2010. Development of the Shipborne Rolling Vertical Landing (SRVL) Manoeuvre for the F-35B Aircraft. In: Proceedings of the International Powered Lift Conference, Philadelphia, PA.

Cooper, K. R., 1985. The Effect of Front-Edge Rounding and Rear-Edge Shaping on the Aerodynamic Drag of Bluff Vehicles in Ground Proximity. In: SAE Technical Paper 850288.

Denham, J. W., 2016, Project MAGIC CARPET: Advanced Controls and Displays for Precision Carrier Landings. In: Proceedings of $54^{\text {th }}$ AIAA Aerospace Sciences Meeting, San Diego, California.

Du Val, R. W., He, C., 2018. Validation of the FLIGHTLAB virtual engineering toolset. In: The Aeronautical Journal, Vol. 122(1250), pp 519-555.

Finlay, B., 2001. Ship Helicopter Operating Limit Testing - Past, Present and Future. In: Proceedings of the RAeS Rotorcraft Group Conference on 'Helicopter Operations in the Maritime Environment', London, UK.

Forrest, J. S., Owen, I., 2010. Investigation of Ship Airwakes using Detached-Eddy Simulation. In: Computers \& Fluids, Vol. 39(4), pp 656-673.

Fry, A., Cook, R., Revill, N., 2009. CVF ski-jump ramp profile optimisation for F-35B. In: The Aeronautical Journal, Vol. 113 (1140). pp 79-85.

Garrett, R., 1992. The atmospheric boundary layer. Cambridge Atmospheric and Space Science Series, Cambridge University Press, UK.

Haller, G., 2005. An objective definition of a vortex. In: J. Fluid Mechanics, Vol. 525, pp. 1-26.

Hess, R. A., 2018. Providing Flight-Path Control Bandwidth for Carrier Landings. In: Journal of Aircraft, Vol. 55(1). pp 404-409.

Hodge, S. J., 2004. Validation of Shipborne Visual Landing Aids Through Piloted Simulation. In: Proceedings of the RAeS Flight Simulation Group Conference on 'Simulation of Onboard Systems', London, UK.

Hodge, S. J., Wilson, P. N., 2008. Operating JSF from CVF the Reality of Simulation. In: Proceedings of the International Powered Lift Conference, London, UK.

Hodge, S. J., Forrest, J. S., Padfield, G. D., Owen, I., 2012. Simulating the environment at the helicopter-ship dynamic interface: research, development and application. In: The Aeronautical Journal, Vol. 116 (1185). pp $115-1184$

Hodge, S. J., Spencer, M. P., Southworth, M. R., 2013. A Collaborative Simulation Environment for Investigating Aircraft-Ship Operations. In: Proceedings of the RAeS Flight Simulation Group Conference on 'Mission Training and Flight Simulation - Technology, concepts and collaboration', London, UK.

Hodge, S. J., Perfect, P., Padfield, G. D., White, M. D, 2015. Optimising the roll-sway motion cues available from a short-stroke hexapod motion platform. In: The Aeronautical Journal, Vol. 119 (1211), pp. 23-44.

Hucho, W. H., Janssen, L. J., Emmelmann, H. J., 1976. The Optimization of Body Details - A Method for Reducing the Aerodynamic Drag of Road Vehicles. In: SAE Technical Paper 760185.

Kelly, M. F., 2018. The Development, Validation, and Integration of Aircraft Carrier Airwakes for Piloted Flight Simulation. In: PhD Thesis, University of Liverpool, UK.

Kraus, N. C., Lohrmann, A., Cabrera, R., 1994. New Acoustic Meter for Measuring 3d Laboratory Flows. In: Journal of Hydraulic Engineering, Vol. 120(3). pp 406-412. 


\section{Uncontrolled}

Lison, A., 2009. Integrating the Joint Combat Aircraft into the Queen Elizabeth Class Aircraft Carriers - Design Challenge or Opportunity? In: Proceedings of Warship 2009 - 'Airpower at Sea', London, UK.

Owen, I., White, M. D., Padfield, G. D., Hodge, S. J., 2017. A virtual engineering approach to the ship-helicopter dynamic interface - a decade of modelling and simulation research at the University of Liverpool. In: The Aeronautical Journal, Vol. 121(1246), pp 1833-1857.

Polsky, S., Naylor, S., 2005. CVN Airwake Modeling and Integration: Initial Steps in Creation and Implementation of a Virtual Burble Model for F-18 Carrier Landing Simulation. In: Proceedings of AIAA Modeling and Simulation Technologies Conference, San Francisco, California.

Roscoe, A. H., Ellis, G. A., 1990. A Subjective Ratings Scale for Assessing Pilot Workload in Flight: A Decade of Practical Use. In: RAE Technical Report, RAE-TP-90019.

Spalart, P. R., Deck, S., Shur, M. L., Squires, K. D., Strelets, M. Kh., Travin, A., 2006. A New Version of Detached-Eddy Simulation. In: Computers \& Fluids, Vol. 39(3), pp 181-195.

Voulgaris, G., Trowbridge, J. H., 1998. Evaluation of the Acoustic Doppler Velocimeter (ADV) for Turbulence Measurements. In: Journal of Atmospheric and Oceanic Technology, Vol. 15(1), pp 272-289.

White, M. D., Perfect, P., Padfield, G. D., Gubbels, A. W., Berryman, A. C., 2012. Acceptance testing and commissioning of a flight simulator for rotorcraft simulation fidelity research. In: Proceedings of the IMechE Part G: Journal of Aerospace Engineering, Vol. 226(4), pp 638-686. 